MarketiNG AND BRANDING
RESEARCH $\begin{gathered}\text { INDUSTRIAL } \\ \text { MANAGEMENT } \\ \text { INSTITUTE }\end{gathered}$

\title{
The impact of product's packaging color on customers' buying preferences under time pressure
}

\author{
Saad Ahmed Javed ${ }^{*}$, Sara Javed ${ }^{2}$ \\ ${ }^{1}$ Academy of Young Researchers and Scholars, Lahore, Pakistan \\ ${ }^{1}$ Lahore School of Management, the University of Lahore, Lahore, Pakistan \\ ${ }^{2}$ Academy of Young Researchers and Scholars, Lahore, Pakistan
}

\begin{abstract}
Keywords:

Packaging, Color, Buying Behavior, Time Pressure, Buying Preference, Marketing

Correspondence: saad.ahmed.javed@live.com

This research aims to test whether product's packaging color influences customers' purchasing preferences or not and does time pressure moderates this relationship? It studied the importance of color in determining customers' buying preferences when they have limited time to do shopping. This study revealed that buying preference of a customer is relatively more dependent on the color scheme than on time constraint. However, time pressure was an important moderating factor which influenced the effect of packaging colors on customers' purchasing preferences. This study emphasized that companies cannot afford to ignore the significance of time constraints and color scheme of the products on customers' buying behavior.
\end{abstract}

\section{Introduction}

Packaging plays a decisive role in marketing communication. The right color can clinch the sale and a wrong color can fall short. Is this the fact or the fiction? According to Silayoi \& Speece (2007) only a tiny section of customers focus on product details or labels as some customers are typically influenced by the visual aesthetics. Firms strive to increase their market offerings to meet their customers' needs more effectively and in doing so they attempt to influence customers' perception and behavior by 
associating certain colors with their products and campaigns that may appeal the existing and potential customers.

While discussing customers' appraisal of products, Singh (2006) revealed that around sixty to ninety percent of the appraisal is driven exclusively by colors. Color is a central element of products, services, packages, logos, displays, and collaterals which influences perceptions (Aslam, 2006). Colors can play roles not only in forming consumers' brand perceptions (Labrecque \& Milne, 2012) but also in customers' responding and purchasing behavior which is independent of brand preferences (Clement, 2007). In fact, a study on nail polish suggested that overwhelming possibility of brands' colors in term of seeking customers' attention cannot be ignored (Sun, Adhikari, \& Koppel, 2015). Colors on packaging may cause apprehension and even rejection by customers (Prinsloo, Merwe, Bosman, \& Erasmus, 2012); therefore, packaging colors may cause strategic failure if they are not properly chosen (Aslam, 2006). Labrecque \& Milne (2012) showed that colors can be used strategically to influence buying intentions, personality, and congeniality of a brand. Though the colors affect customer personality, they are usually overlooked by conventional psychologists but psychiatrists employ color tests alongside other tests to gauge personality (Singh, 2006). Colors have been used by packagers to influence perceptions of package weight and to create psychological meaning (Bellizi \& Hite, 1992). Thus it can be argued that color of packaging makes a significant contribution in altering potential customers' buying desires and preferences concerning shopping.

Further, it must be understood that customers are time-constrained and cannot allow themselves exhausting excessive time in forging purchase decisions (Reutskaja, Nagel, Camerer, \& Rangel, 2011) hence the study aims to propagate the need of effective deployment of proper packaging color to influence purchasing decisions of time pressured customers considering it a very crucial for designers, manufacturers and marketers today. The purpose of the study was to check whether product's packaging color influences customers' buying behavior or not and does time pressure moderates this relationship? Thus, the study fills the perceived gap in the literature concerning the buying behavior of Pakistani customers under time constraints and is discussed in detail in the following sections.

\section{Packaged Goods and Pakistan}

Pakistan offers an outstanding milieu to explore packaging of packed goods. Even the most traditional goods, like the drinking water which has no history of packaging in the region are now available in packaging bottles in Pakistani markets to meet the demand of consumers who are becoming more demanding with the passage of time. Silayoi \& Speece (2004) in their study on packaged food products have stressed on the need of understanding Asian customers' reactions to packaging considering its importance for organizations contesting internationally. Earlier there were foreign FMCG companies that promoted packaged goods in the region but now local manufacturers are also introducing their products in eye-catching design packaging to fight off the ever-increasing 
competition. In modern days, packaging plays a pivotal role in the production of goods and marketing communication; therefore, with the growth of vending in Pakistan the role of packaging in attracting new customers and retaining existing ones is becoming increasingly important. Packaging with bright colors is more likely to gain customers' attention than dull colors and thus designing packaging while considering local culture is useful (Aslam, 2006).

\section{Packaging Color and Customers' Buying Preferences}

Color research paid little attention in the field of marketing (Labrecque, Patrick, \& Milne, 2013) and effects of different colors on consumers' choices. Consumers' perceptions have been overlooked in literature in spite of the fact that most product assessments by customers are based on colors alone (Funk \& Ndubisi, 2006; Singh, 2006). Borgogno et al. (2015), in their study on meat, have identified color as one of the intrinsic quality cues strongly associated with customers' expectations while shopping. Skorinko, Kemmer, Hebl, and Lane (2006) in their study on naming products/brands have shown that although names significantly influence on the customers' perceptions concerning colors still the name associated with a color is of secondary importance when the color itself seeks primary importance for the customers. Frank et al. (2001) in their research involving a medicine's colors showed that color was about three times more important than retail price in shaping consumers' purchase decisions.

Packaging color plays an extremely vital role in communicating with customers. Funk \& Ndubisi (2006) have stressed that colors can arouse the interest in a product and can motivate customers toward its buying. They defined five dimensions of color as following, including color significance, attitude towards color, color attractiveness, normative color, and color preferences. Color significance states that not all colors have same significance for customers. For instance, white is linked to peace while green seems cool. Attitude towards a product color will predict their shopping behavior. Furthermore, customers are more likely to remember colored portion of ads than non colored portion. In normative color, customers seek to influence from external factors or environment. Customers may prefer certain colors over others in different products. For example, a color which a customer prefers for automobiles may not be preferred for furniture. Color preferences predict customer's buying preferences in an outlet.

Skorinko et al. (2006) have identified three main color preferences that a color performs well for low involvement, fast moving, and consumer goods which may not suit for high involvement purchasing decisions by customers (Basera, Mutsikiwa, \& Dhliwayo, 2013). The proper use of colors aids in distinguishing and directing the attitude towards that product (Singh, 2006); however, it was also noted that color of packaging can also be misleading. For instance, Muttie et al. (2011) reported that 20 per cent of the cigarettes' consumers believe that cigarettes labeled as light are less hazardous than the cigarettes labeled as dark. Therefore, by properly studying the importance of product's 
packaging color for customers and how it affects customers' purchasing intentions, preferences, and decisions, marketers can effectively retain and satisfy their customers' requirements.

\section{Time Pressure}

Life is getting busier and busier with the passage of time. No customer wants to spend unnecessary time in purchasing goods. Singh (2006) reports that within ninety seconds of their preliminary communication with individuals or goods, people arrive at conclusion. Majority of the customers put up their purchase decisions swiftly with minor quest or price juxtaposition attempts which make time for them a well prized customer resource (Cohen \& Babey, 2012; Herrington \& Capella, 1995).

Time constraint or time pressure pertains to customers' susceptibility to look at time as a scantly capital and intend using it efficiently (Konus, Verhoef, \& Neslin, 2008). It is extensively considered and evaluated as a situational variable determining customers' decision making within a shop (Lin \& Chen, 2013). Herrington and Capella (1995) have demonstrated that time constraints in some way influence customers' shopping behavior and shoppers exhibit different shopping behavior under different levels of time pressure conditions. Time-pressured shoppers generally do not conduct extensive research because time constraints curtail comprehensive examination of package elements (Konus et al., 2008; Silayoi \& Speece, 2004). As in an ordinary twenty minutes shopping expedition, a customer reads merely eight lines or less, thus communication is being done largely by virtue of colors, visual illustrations, and shapes (Cohen \& Babey, 2012). Thus importance of packaging elements such as color, background image, and design of wrapper increase as time is recognized as exceedingly scarce resource. Silayoi \& Speece (2004) suggested that time constraint is destined to become constantly much significant component which marketers ought to consider while designing a product's packaging.

\section{Research Hypotheses}

In line with the discussion above, the following three research hypotheses were formulated:

$\mathbf{H}_{1}$ : Color usage $(\mathrm{CU})$ in packaging and Customers' buying preferences (CBP) are positively and significantly linked.

$\mathbf{H}_{2}$ : Time pressure (TP) and customers' buying preferences (CBP) are positively and significantly linked.

$\mathbf{H}_{3}$ : Color usage (CU) in packaging and customers' buying preferences (CBP) are positively and significantly linked under the moderating effect of time pressure (TP).

\section{Conceptual Framework}

In light of the literature review, the study includes two variables including color usage and time pressure for finding the effect of both variables on customers buying preferences. The research aims 
to find out that whether the buying preferences of customers varies due to changes in color usage of particular product due to its package design or not and to what extent. First, the effect of color usage in products package design on consumers' buying preferences was gauged. Secondly, the effect of time pressure on the consumers' buying preferences was measured. The aim was to find the impact of product's package design element (color) on customers' buying preferences under time constraints. After measuring the impact of both variables separately, we found out the multiplier effect of time pressure and color usage in the products package design on consumers' buying preferences.

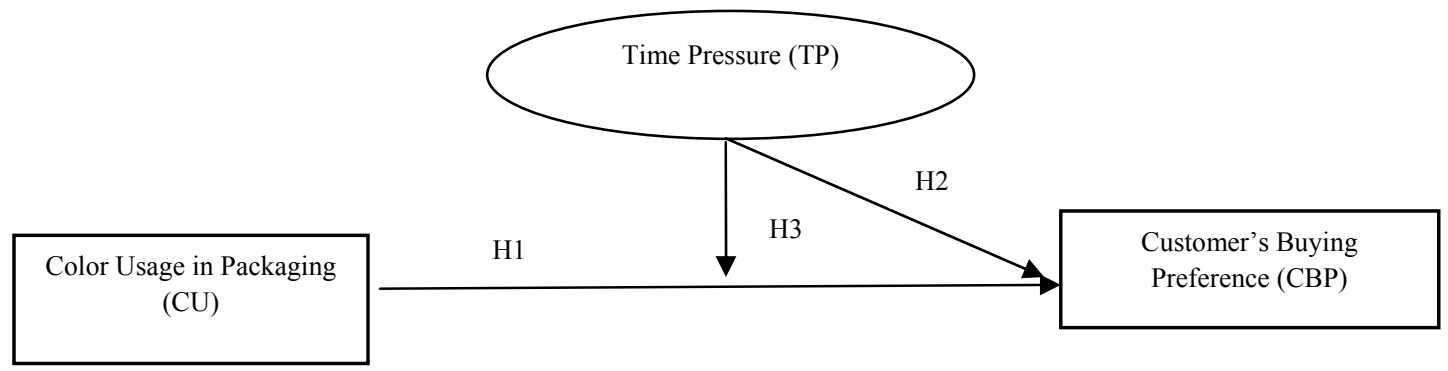

Figure 1. The research framework

\section{Method}

A self-administered survey was deployed in the study. The questionnaire consisted of two parts. In each part, 5-point Likert Scale was employed ranged from least agreed (1) to most agreed (5). Both parts contain eight research items in total, borrowed from Silayoi \& Speece (2004) with slight necessary modifications to gauge time-pressured customers' buying behavior regarding packaging colors of hair care products (shampoo and hair conditioner) and then to gauge time-pressured customers' buying behavior regarding packaging colors of skin care products (face wash and moisturizer). The questionnaire contained eight items in both parts and three variables were being studied. No question regarding the identity of respondents was asked to maintain the confidentiality.

The survey questions were written in English and were translated back into Urdu to help nonEnglish speaking respondents. Hard copies of structured questionnaires were being distributed among 215 female respondents of Lahore, in 2013, and at least one of the authors was present at the scene. Out of these, 202 questionnaires were properly filled out and selected for data analysis. All the respondents were undergraduate engineering and business university students aged 18 to 25 . For data collection customers of skin and hair care products were selected. The reason for selecting only females in the study was that in most of the countries particularly in South Asian markets females are mostly responsible for doing shopping whether for themselves or for their household. To gain deeper insights into buying behavior, we deliberately choose products that are mostly specific to females. Further, a study conducted by Sun, Adhikari, \& Koppel (2015) suggested that not much customer insight data on color cosmetics is available in literature. Shampoo and hair conditioner were considered as hair care products while face wash and moisturizer were taken as skin care products. 


\section{Results}

To check the validity and reliability of questionnaire and test hypotheses correlation and linear regression analysis were utilized for data analysis using SPSS, the most popular statistical software being used in business schools of Pakistan. Following the tradition in business research and owing to its predictors-based forecasting ability, regression analysis was deployed to gauge the strength of association of independent variable and moderator to dependent variable using the latest version of SPSS. Reliability of questionnaires and research items was estimated by using Cronbach's alpha. For each research item reliability was satisfactory. The reliability coefficient were $0.87,0.71$ and 0.69 for research items concerning variation in customers' buying preference due to packaging color, preference variation due to time pressure and then preference variation due to packaging color in the presence of time pressure, respectively, as shown in Table 1. Therefore, reliability and validity of questionnaire was satisfactory.

Table 1

Reliability Statistics

\begin{tabular}{cc}
\hline Cronbach's Alpha & Number of Items \\
\hline 0.87 & $4^{\mathrm{a}}$ \\
0.71 & $3^{\mathrm{b}}$ \\
0.69 & $1^{\mathrm{c}}$ \\
\hline a. & research items gauging variation in CBP due to CU \\
b. $\quad$ research items gauging variation in CBP due to TP & \\
c. & research item gauging variation in CBP due to multiplicative factor of CU \& TP
\end{tabular}

The result of regression analysis illustrated the dependence of customers' buying preferences on color usage with moderating role of time pressure. The impact of color usage on consumers' buying preferences was sought through the analysis shown in Tables 2, 3, and 4. Table 2 shows that $\mathrm{R}$ square value was 0.21 which depicted that the variation in consumer's buying preference (dependent variable) was due to color usage (independent variable).

Table 2

Model Summary

\begin{tabular}{ccccc}
\hline Mode & $\mathrm{R}$ & $\mathrm{R}^{2}$ & Adjusted R Square & Standard Error of the Estimate \\
\hline 1 & $0.46^{\mathrm{a}}$ & 0.21 & 0.21 & 0.69 \\
\hline
\end{tabular}

a. Predicators: (Constant), CU

In Table 3, F value was 41.59 showing that model is a good fit.

Table 3

The Results of ANOVA ${ }^{a}$

\begin{tabular}{ccccccc}
\hline & Model & Sum of Squares & df & Mean Square & F & \\
\hline \multirow{2}{*}{1} & Regression & 20.31 & 1 & 20.31 & 41.59 & \\
& Residual & 72.26 & 148 & 0.48 & \\
& Total & 92.57 & 149 & & \\
\hline
\end{tabular}

a. Dependent Variable: CBP

b. Predictors:(Constant), $C U$ 
As Table 4 depicts, $t$-value showed that color usage was a useful predictor of consumer's buying preference though there was a moderate positive relationship. The $p$ value was less than 0.05 and the value of correlation coefficient was 0.46 which showed that independent variable (color usage) had positive but moderate relationship with dependent variable (consumers' buying preferences). Thus, first hypothesis was confirmed.

Table 4

Coefficients $^{a}$

\begin{tabular}{|c|c|c|c|c|c|}
\hline \multirow[t]{2}{*}{ Model } & \multicolumn{2}{|c|}{ Non- Standardized Coefficients } & \multirow{2}{*}{$\begin{array}{c}\text { Standardized Coefficients } \\
\text { Beta }\end{array}$} & \multirow[t]{2}{*}{$\mathrm{T}$} & \multirow[t]{2}{*}{ Sig. } \\
\hline & B & Std. Error & & & \\
\hline (Constant) & 1.17 & 0.29 & & 4.01 & 0.00 \\
\hline \multicolumn{6}{|l|}{1} \\
\hline $\mathrm{CU}$ & 0.52 & 0.08 & 0.46 & 6.45 & 0.00 \\
\hline
\end{tabular}

Table 4 provides the following equation that related color usage in packaging to consumers' buying preferences:

$$
\mathrm{CBP}=0.52(\mathrm{CU})+1.17
$$

The insight of the effects of time constraints on consumers' buying preferences was sought through the analysis shown in Tables 5, 6, and 7. Table 5 showed that R square value was 0.07 which depicted that 7.1 per cent of variance in consumer's buying preference was due to time pressure. Furthermore, Table 6 showed that $F$ value was 11.29 showing that model was good fit.

Table 5

Model Summary

\begin{tabular}{ccccc}
\hline Mode & $\mathrm{R}$ & $\mathrm{R}^{2}$ & Adjusted $\mathrm{R}^{2}$ & Std. Error of the Estimate \\
\hline 1 & $0.26^{\mathrm{a}}$ & 0.07 & 0.06 & 0.76 \\
\hline
\end{tabular}

a. Predictors: (Constant), TP

Table 6

ANOVA $^{a}$

\begin{tabular}{lccccc}
\hline Model & Sum of Squares & df & Mean Square & F & Sig. \\
\hline Regression & 6.56 & 1 & 6.56 & 11.29 & $0.001^{\mathrm{b}}$ \\
Residual & 86.01 & 148 & 0.58 & & \\
Total & 92.57 & 149 & & & \\
\hline
\end{tabular}

a. Dependent Variable: CBP

b. Predictors: (Constant), TP

The $p$ value was less than 0.05 and the value of $\mathrm{R}$ is 0.26 which showed that independent variable (time pressure) had positive but weak relationship with dependent variable (consumer's buying preference). The $t$-value was significant thus making time pressure a useful predictor of consumer's buying preference. Hence, second hypothesis was confirmed. 
Table 7

Coefficients $^{a}$

\begin{tabular}{cccccc}
\hline Model & \multicolumn{2}{c}{ Non-Standardized Coefficients } & Standardized Coefficients & T & Sig. \\
& $\mathrm{B}$ & Std. Error & Beta & & 0 \\
\hline (Constant) & 2.21 & 0.24 & & 9.05 & 0.00 \\
1 TP & 0.24 & 0.07 & 0.26 & 3.36 & 0.00 \\
\hline
\end{tabular}

a. Dependent Variable : CBP

Following relation was generated form Table 7 that related time pressure to consumers' buying preferences:

$$
\mathrm{CBP}=0.24(\mathrm{TP})+2.21
$$

The insight of the moderating impact of time constraints on the association between color usage and consumers' buying preferences was seek through the analysis shown in Tables 8, 9 and 10. The $p$ value was less than 0.05 . The $\mathrm{R}$ was 0.54 which can be translated as a positive but moderate relation between independent variable (combined effects of color usage and time pressure) and dependent variable (consumers' buying preferences). But the analysis, as shown in the Table 10, suggested that the mutual interaction of independent variables (time pressure and color usage) had shown a moderate positive relationship with dependent variable (consumers' buying preferences). Thus it can be argued that time pressure acted as a moderating variable in this particular scenario. Hence, third hypothesis was also accepted.

Table 8

Model Summary

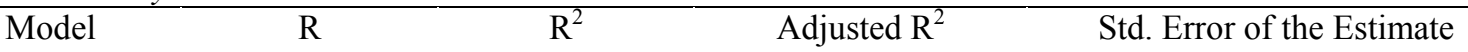

\begin{tabular}{lllll}
\hline 1 & $0.549^{\mathrm{a}}$ & 0.30 & 0.28 & 0.667 \\
\hline
\end{tabular}

Table 9

ANOVA ${ }^{a}$

\begin{tabular}{cccccc}
\hline Model & Sum of Squares & df & Mean Square & F & Sig. \\
\hline Regression & 27.902 & 3 & 9.30 & 20.99 & $.000^{\text {b }}$ \\
Residual & 64.677 & 146 & 0.44 & & \\
Total & 92.579 & 149 & & & \\
\hline
\end{tabular}

a. Dependent Variables: CBP

b. Predictors: (Constant), Multiplication, $\mathrm{CU}, \mathrm{TP}$

Table 10

Coefficients $^{a}$

\begin{tabular}{|c|c|c|c|c|c|}
\hline \multirow[t]{2}{*}{ Model } & \multicolumn{2}{|c|}{ Non-Standardized Coefficients } & \multirow{2}{*}{$\begin{array}{c}\text { Standardized Coefficients } \\
\text { Beta }\end{array}$} & \multirow[t]{2}{*}{$\mathrm{T}$} & \multirow[t]{2}{*}{ Sig. } \\
\hline & B & Std. Error & & & \\
\hline (Constant) & 2.43 & 0.90 & & 2.69 & 0.00 \\
\hline $\mathrm{TP}$ & -0.37 & 0.26 & -0.40 & -1.39 & 0.16 \\
\hline $\mathrm{CU}$ & -0.03 & 0.25 & -0.03 & -0.15 & 0.87 \\
\hline Multiplicatior & & & & & \\
\hline $1 \mathrm{n}$ & 0.167 & 0.07 & 0.84 & 2.28 & 0.02 \\
\hline
\end{tabular}

a. Dependent Variable: CBP 


\section{Discussion and Conclusion}

Can companies afford to ignore packaging colors when communicating with customers? Color of packaging plays a very important role in decision making by customers to purchase a good. When there are time constraints during shopping, the preferences of customers vary and thus their buying behaviors vary. For instance, time pressure can result into quick buying decisions and this decision may or may not be right. This study involved two independent variables, i.e., time pressure and color usage in packaging product design. The results showed that the color usage had significant moderate positive relation with consumer's buying preferences while time pressure had significant weak positive relation with consumer's buying preferences. The results also validated the moderating effects of time pressure on consumer's buying preferences indicating that time pressure was important factor which influenced the effect of visual package element on consumer's buying decisions. Therefore, buying preference of a customer was relatively more dependent on color scheme than on time constraints. However, time constraints moderately influenced the relationship between color schemes of products and buying preferences of customers in Pakistan. It was observed that most of the consumers' preferences vary with the color scheme used in the products packaging design. In shops or markets, when consumers were supposed to do shopping quickly under time pressure, they were mostly influenced by attractive products' colorful packaging that in turn could influence number of sales as well. Consumers' perceptions regarding different products were influenced by their experiences with the colors used in packaging. This initial perception derived their decision of whether to purchase or not the product or service. The study revealed the importance of much ignored area of marketing communication management. With increasing competition, customers had more alternatives and less time for choosing and purchasing a product.

Finally, though different studies (Hasan \& Khan, 2009; Seher, Arshad, Ellahi, \& Shahid, 2012; Zaidi \& Muhammad, 2012; Shah, Ahmed, \& Ahmad, 2013; Saeed, Lodhi, Rauf, Rana, Mahmood, \& Ahmad, 2013; Adam, \& Ali, 2014; Ahmed, Parmar, \& Amin, 2014) have been undertaken in Pakistan related to buying behavior or packaging characteristics but the contribution of time pressure in the packaging-behavior relationship has been largely ignored in the literature. There was also no significant study involving female products, in aforementioned context. The study bridges the gap and suggests that marketers, business managers, and entrepreneurs cannot afford ignoring the significance of time constraints and color schemes of the products' packaging in bringing variation in customers' buying preferences.

\section{Limitations and future research implications}

Since the study particularly involved female products and only young female respondents were interviewed thus it restrains marketing professionals and future researchers from generalization the 
findings for all products and genders. How men and senior women could influence the research outcomes for different products is yet to be seen. Further, the study was conducted in the provincial capital of Pakistan hence how research findings could vary if similar research is undertaken in different environment is area of future research.

\section{Acknowledgement}

The authors want to thank the journal editors and reviewers for their suggestions and comments on the earlier version of the manuscript.

\section{References}

Adam, M. A., \& Ali, K. (2014). Impact of Verbal Elements of Packaging of Packaged Milk on Consumer Buying Behavior. International Journal of Business and Social Science, 5(5), 1.

Ahmed, R. R., Parmar, V., \& Amin, M. A. (2014). Impact of Product Packaging on Consumer's Buying Behavior. European Journal of Scientific Research, (122), 125-134.

Aslam, M. M. (2006). Are you selling the right colour? A cross-cultural review of colour as a marketing cue. Journal of Marketing Communications, 12(1), 15-30.

Basera, C. H., Mutsikiwa, M., \& Dhliwayo, K. (2013). A comparative study on the impact of ambient factors on patronage: A case of three fast foods retail brands in Masvingo, Zimbabwe. International Journal for Innovation, Education, \& Research, 1(1), 115-124.

Bellizzi, J. A., \& Hite, R. E. (1992). Environmental color, consumer feelings, and purchase likelihood. Psychology \& Marketing, 9(5), 347-363.

Borgogno, M., Favotto, S., Corazzin, M., Cardello, A. V., \& Piasentier, E. (2015). The role of product familiarity and consumer involvement on liking and perceptions of fresh meat. Food Quality \& Preference, 44, 139-147.

Clement, J. (2007). Visual influence on in-store buying decisions: An eye- track experiment on the visual influence of packaging design. Journal of Marketing Management, 23(9/10), 917-928.

Cohen, D. A. \& Babey, S.H. (2012). Contextual influences on eating behaviours: Heuristic processing and dietary choices. Obesity Reviews, 13(9), 766-779.

Frank, C. A., Nelson, R. G., Simonne, E. H., Behe, B. K., \& Simonne, A. H. (2001). Consumer preferences for color, price, and vitamin C content of Bell Peppers. Hortscience, 36(4), 795-800.

Funk, D., \& Ndubisi, N. O. (2006). Colour and product choice: A study of gender roles. Management Research News, 29(1/2), 41-52.

Hasan, S. A., \& Khan, M. Z. (2009). The Impact of Packaging Characteristics on Consumer Brand Preference. South Asian Journal of Management Sciences, 3(1), 1-10.

Herrington, J. D., \& Capella, L. M. (1995). Shopper reactions to perceived time pressure. International Journal of Retail \& Distribution Management, 23(12), 13-20.

Konus, U., Verhoef, P. C., \& Neslin, S. A. (2008). Multichannel shopper segments and their covariates. Journal of Retailing, 84(4), 398-413.

Labrecque, L. I., \& Milne, G. R. (2012). Exciting red and competent blue: The importance of color in marketing. Journal of Academy of Marketing Science, 40(5), 711-727.

Labrecque, L. I., Patrick, V. M., \& Milne, G. R. (2013). The marketers' prismatic palette: A review of color research and future directions. Psychology \& Marketing, 30(2), 187-202.

Lin, Y. H., \& Chen, C. F. (2013). Passengers' shopping motivations and commercial activities at airports: The moderating effects of time pressure and impulse buying tendency. Tourism Management, 36, 426-434.

Mutti, S., Hammond, D., Borland, R., Cummings, M. K., O’Connor, R. J., \& Fong, G. T. (2011). Beyond light and mild: Cigarette brand descriptors and perceptions of risk in the International Tobacco Control (ITC) Four Country Survey. Addiction, 106(6), 1166-1175. 
Prinsloo, N., Merwe, V. D., Bosman, M., \& Erasmus, A. (2012). A critical review of the significance of food labeling during consumer decision making. Journal of Family Ecology \& Consumer Sciences, 40, 83-98.

Reutskaja, E., Nagel, R., Camerer, C. F., \& Rangel, A. (2011). Search dynamics in consumer choice under time pressure: An eye-tracking study. American Economic Review, 101(2), 900- 926.

Saeed, R., Lodhi, R. N., Rauf, A., Rana, M. I., Mahmood, Z., \& Ahmed, N. (2013). Impact of Labelling on Customer Buying Behavior in Sahiwal, Pakistan. World Applied Sciences Journal, 24(9), 1250-1254.

Seher, T., Arshad, M., Ellahi, S., \& Shahid, M. (2012). Impact of colors on advertisement and packaging on buying behavior. Management Science Letters, 2(6), 2085-2096.

Shah, S., Ahmed, A., \& Ahmad, N. A. W. A. Z. (2013). Role of Packaging in Consumer Buying Behavior. International Review of Basic and Applied Sciences, 1(2), 35-41.

Silayoi, P., \& Speece, M. (2004). Packaging and purchase decisions: An exploratory study on the impact of involvement level and time pressure. British Food Journal, 106(8), 607-628.

Silayoi, P., \& Speece, M. (2007). The importance of packaging attributes: A conjoint analysis approach. European Journal of Marketing, 41(11/12), 1495-1517.

Singh, S. (2006). Current research development: Impact of color on marketing. Management Decision, 44(6), 783-789.

Skorinko, J. L., Kemmer, S., Hebl, M. R., \& Lane, D. M. (2006). A rose by any other name: Color naming influences on decision making. Psychology \& Marketing, 23(12), 975-993.

Sun, C., Adhikari, K., \& Koppel, K. (2015). An exploratory study of the factors that may affect female consumers' buying decision of nail polishes. Cosmetics, 2(2), 187-195.

Zaidi, S., \& Muhammad, B. (2012). Awareness of Pakistani consumers towards nutritional labeling on product packaging in terms of buying behavior. International Journal of Business and Social Science, 3, 97-103. 